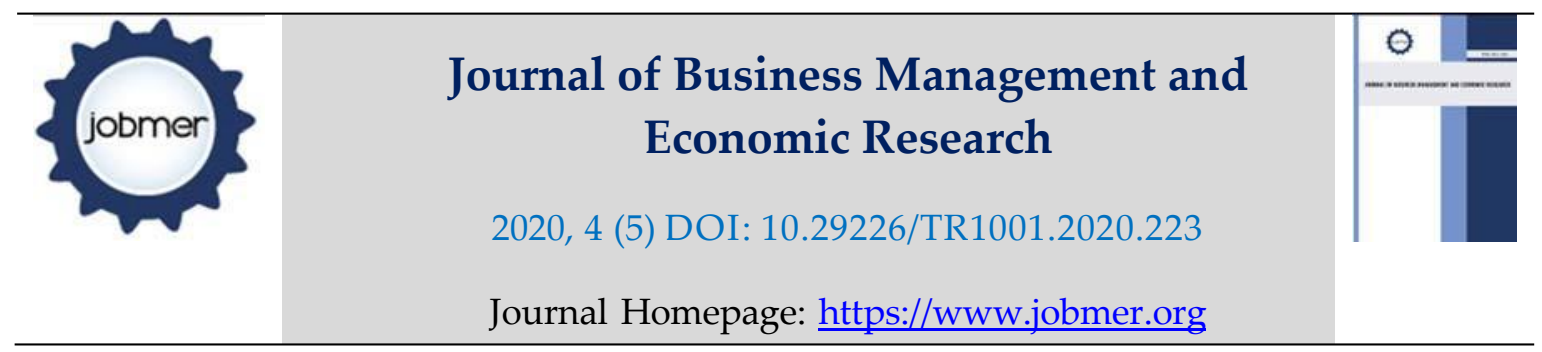

\title{
Effect of Anchoring Heuristic on Financial Performance of Small and Medium Enterprises in Nairobi, Kenya: The mediating role of Investment Decisions
}

\author{
Alex Koech \\ Department of Finance and Accounting, Moi University, Kenya \\ drfernando173@gmail.com
}

\begin{abstract}
The psychological or behavioral heuristics affects investors' way of deciding on investment and therefore affecting the financial performance of the firm. This effect varies subject to the investor's nature which in turn affects the financial performance of the firm. Using cross-sectional data from 382 respondents of Small and Medium Enterprises within Nairobi County, the study evaluates direct effect of Anchoring Heuristic on financial performance of the SMEs in Nairobi County. Additionally, the study scrutinizes the mediational role of Investment decisions on the relationship between anchoring heuristic and financial performance of the said SMEs. The study is grounded in Heuristic theory together with Modern portfolio theory. The study used Explanatory research design and arranged the samples into strata. Data was collected using self-administered, structured questionnaires and items were grounded on a five-point Likert scale with data analysis being done using descriptive and inferential statistics. The hypotheses of the study were tested using multiple regression models and Hayes process macro. The results showed that Anchoring Heuristics significantly predicts SME's financial performance $(\beta=.129, \mathrm{p}<.05)$ and this relationship is partially mediated by Investment decisions $(\beta=.239, \mathrm{p}<.001, \mathrm{CI}=0.029,0.112)$. Theoretically, the study supported the incorporation of the key heuristic factor (anchoring), and investment decisions, where the outcome of the results indicated the significant relationship in achieving financial performance of SMEs. Finally, there is need to undertake similar studies covering other geographical locations to make generalization of this study.
\end{abstract}

Keywords: Heuristic behavior, Anchoring, Investment decisions, Financial performance.

\section{Suggested Citation:}

Koech, A. (2020). Effect of Anchoring Heuristic on Financial Performance of Small and Medium Enterprises in Nairobi, Kenya: The mediating role of Investment Decisions. Journal of Business Management and Economic Research (JOBMER), Vol: 4, Issue: 5, 


\section{Introduction}

Investors think and behave "rationally" when buying and selling goods and services. They are presumed to use all available information to form "rational expectations" about the future in determining the financial performance and the general health of the firm. However, according to Shiller (2008) investors do not think and behave rationally. To the contrary, driven by greed and fear, investors speculate stocks between unrealistic highs and lows. In other words, investors mislead by extremes of emotion, subjective thinking and the whims of the crowd, consistently form irrational expectation for the future performance of companies and the overall economy such that stock prices swing above and below fundamental values and follows a somewhat predictable, wave-like path. Anchoring heuristic is the tendency to hold on to a belief and then apply it as a subjective reference point for making future judgments. The anchoring heuristic came out of the observation that decision-makers tend to solve problems by forming a-priori estimates of what the answer might be (Mussweiler, 2002). Ross and Westerfield, (2008) discovered, most investors tend to have a personal and emotional attachment to the asset they hold.

Small and medium enterprises (SMEs) play a very important role in the economies of both developed and developing countries. This role, however, depends on the financial performance and the investment decisions made by each enterprise. Many studies have examined how different personality characteristics of owner/managers in SMEs affect the financial performance of their enterprises (Ibrahim and Goodwin, 1986; Kotey \& Meredith, 1997). Mentality of the owner/managers is an important aspect of their personality characteristics however no prior study has made any attempt to examine its possible impact on the financial performance of their businesses.

Investment Decision relates to the decision made by the investors or the top-level management with respect to the amount of funds to be deployed in the investment opportunities (Lambert, 2012). Due to lack of access to the latest technology in data analytics, the investment decisions in SMEs are based on the owner/manager's experience and personal judgment (Kourtidis, et al., 2011). The decision makers in SMEs are influenced by different behavioral heuristics like representativeness, anchoring, overconfidence and availability heuristic.

\section{Theoretical review}

Heuristic theory and modern portfolio theory are the grounding theories for this study. These are the tenets which an individual use in an uncertain situation to make decisions easy and resourceful. Heuristics are useful if time is limited (Waweru et al., 2008) and limited information since irrational people do not collect all information, they just follow some mental shortcuts that make their decision making process easier, simple and efficient (Tversky and Kahneman, 1974).

Anchoring occurs when an individual lets a specific piece of information control his cognitive decision-making process. When presented with new information, the investors tend to be slow to change or the value scale is fixed or anchored by recent observations (Del Missier, et al, 2007). Investors assume that current prices are right and usually use their purchase price as a reference point (Kahneman \& Riepe, 1998). According to Shiller, (2008), investors fix prices in relation to the last price. Anchoring can lead investors to expect a share to continue to trade in a defined range or to expect a company's earnings to be in line with historical trends, leading to possible under-reaction to trend changes. Investors tend to be optimistic in times of good market performance and pessimistic when the market dips.

Markowitz' portfolio selection theory is a 'normative theory.' Fabozzi, et al., (2002) define a normative theory as "one that describes a standard or norm of behavior investors should pursue in constructing a portfolio..." Sharpe's asset pricing theory (CAPM) is regarded as a 'positive theory' - one that 
hypothesizes how investors actually behave as opposed to how they should behave. Together, they provide a theoretical framework for the identification and measurement of investment risk and the development of relationships between expected return and risk.

\section{Conceptual framework.}

A conceptual framework is a figure which the researcher uses to best expound on the natural advancement of the phenomenon being studied (Osanloo, \& Grant, 2016). This is the researcher's explanation of in what manner the research problem would be discovered. It describes the connection between the core concepts of a study. This research seeks to study the mediational effect of investment decisions on the relationship between anchoring heuristic factor and the financial performance of SMEs in Nairobi County.

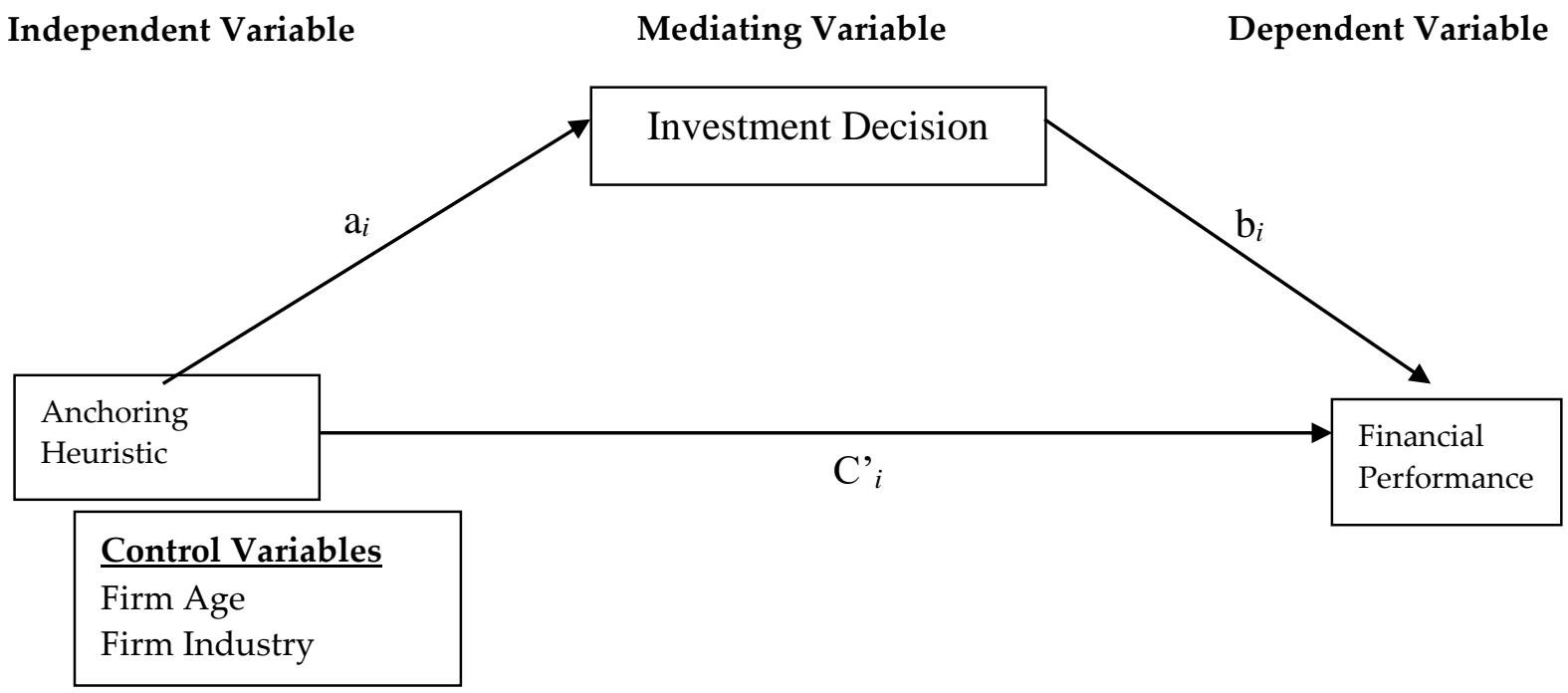

Figure 1: Conceptual Framework

\section{Methodology}

The study embraced an explanatory research design and stratified random sampling techniques to select the SMEs and Industry respectively. Data were collected by use of a closed-ended questionnaire which was self-directed to a sample size of 382 respondents a selection of a target population of 64,443 SMEs in the County of Nairobi, Kenya using (Borg \& Gall, 2014) formula. This study used a positivism research philosophy. Positivists argue that there exist cause-effect association in nature between phenomena, which are predictable with certainty (Garner et al., 2016)

\section{Regression models}

For direct effect with control variables

$F P=\beta_{0}+\beta_{1} F A+\beta_{2} F I+\beta_{3} A N C+\varepsilon \ldots \ldots \ldots \ldots \ldots \ldots \ldots \ldots \ldots \ldots \ldots \ldots \ldots \ldots 1$

Mediation model for the indirect effect

$F P=\beta_{0}+C+\beta_{1} A N C+\beta_{2} I N D+\varepsilon \ldots \ldots \ldots \ldots \ldots \ldots \ldots \ldots \ldots \ldots \ldots \ldots \ldots \ldots .2$

Where; 
$\beta_{\mathrm{o}}$ is the Constant; FA is the Firm age (covariate); FI is the Firm industry (covariate); FP is Financial Performance (DV); ANC is the Anchoring heuristic (IV); IND is the Investment Decision (mediator variable).

\section{Measures}

Financial performance of the study

This is the act of determining the outcomes of a firm's rules and operations in monetarist terms within a certain time frame (Jayawardhana, 2016). Seven items were used in measuring the financial performance adopted from Al-Matari, et al. (2014) with a few adjustments to suit the present research. Every problem was measured on a Likert scale of 1-5 ranging from 5- Strongly agree to 1 - Strongly disagree. The items encompassed; profitability of new ventures, knowledge, and ability of staff to study the market, the current financial responsibilities of the firm, assets being financed by the owners, assets being financed by debt, acceptable profits as a percentage of revenue, part of the total revenue generated by the firm goes to pay interest.

\section{Anchoring heuristic}

Anchoring variable in this study was measured by examining the respondents' extent of agreement with the five-point Likert scale statements on each of the items. Six items were used to measure Anchoring heuristic developed by Babajide and Adetiloye, (2012) with few modifications to suit the current study. The items included; relying on past achievement, effect of recent market experiences on investment decision, benchmarking on the high rate of return achieved in the past, change of investment decision based on the investment patterns, sourcing investment information from friends and relatives, investment decision being affected by recent experiences in the market.

\section{Investment decisions}

Five items were used to measure investment decision variable adapted from Pachur, et al., (2008) and adapted two items from Scott and Bruce, (1995) with a few adjustments to suit the present study. Each problem was measured on a Likert scale of 1-5; 5- Strongly agree, 1- Strongly disagree. These items include being risk-averse on investment, satisfaction on investment decisions and relying on information gathered in groups, having a workable investment plan, regular monitoring of returns on investment, diversification of investment depending on the returns, satisfied with our investment decisions like buying and holding of goods.

\section{Covariates}

To eliminate the effect of covariates, the study controlled two variables (firm age and the industry type). Firm age comprises the number of years of work that the enterprise has existed. The firm age was controlled because previous studies have found a positive relationship with financial performance (Kumar \& Rao, 2015). Firm age was measured using the number of years which the enterprise has been functioning that is the ordinal scale ranging from 1 to 4 (Akben-Selcuk, (2016). Schuckert, et al, (2018) indicates that older firms with longer operating histories make it easier for the investors to estimate their projected future cash flows and therefore help in investment decisions. The industry is the category of business the SMEs fall in. Three industries were identified, manufacturing industry, Merchandising industry and Service industry. The industry was measured by the respondent's answer on which category they fall in. 


\section{Results}

Findings show a response degree of $92.6 \%$, which is above the standard thresh-hold of $50 \%$ as suggested by several researchers. The outcomes point out that $59.3 \%$ of the respondents was of male gender and $40.1 \%$ were of female gender. Regarding the level of education, $20.3 \%$ of the respondents had attained primary education, $25.4 \%$ had acquired secondary education, and $45.8 \%$ studied up to tertiary level while $8.5 \%$ had no education. This indicates a high literacy level among the SMEs Owners/Managers which has consistently been viewed as a type of credential that contributes to informed investment decisions and therefore high financial performance. On the period of operation, the results displayed that the enterprises which have been in existence for less than one year are $28.8 \%$, between 2-3 years were $37.3 \%$, 4-5 years were $22 \%$ and the SMEs which were in existence for more than 5years was $11.9 \%$. This implies that SMEs in Nairobi county are volatile and do not exist for long due to decisions made by the Owners/Managers which affects the financial performance of the businesses.

The results showed that the SMEs who employed less than 5 employees was $49.2 \%$, those who have employed between 6-10 employees were 33.9\%, while those who have more than 11 employees were $16.9 \%$. This means that $49.2 \%$ of the SMEs in Nairobi County fall under the small enterprises. The study further checked on the results of the industry from which the SMEs operate and found that $22 \%$ operates the manufacturing industry, $33.9 \%$ operate the merchandising industry and $44.1 \%$ of the respondents operate in the service industry.

\section{Statistical analysis}

Table 1 below summarizes the means; standard deviations; reliability and correlation results for the variables of this study. The findings show that financial performance has the uppermost mean of 4.89, standard deviation being .522 and the Investment decision has the smallest mean of 4.04 while the standard deviation is .678 . Besides, the scale reliability was within the accepted value, since the Cronbach' Alpha was above .7 for all the variables. The results on correlation disclosed that anchoring heuristic was positively linked with Financial performance with the highest relationship of $r=.408$, $\mathrm{p}<.01$, the investment decision was also positively and significantly related to the financial performance with $\mathrm{r}=.323, \mathrm{p}<.01$. Control variables (firm age and firm industry) also had significant relationship with financial performance $(\mathrm{r}=0.235, \mathrm{p}<0.05$ and $\mathrm{r}=0.612, \mathrm{p}<0.05)$ respectively.

Table 1. Reliability, Means, Standard Deviations, and Correlation results.

\begin{tabular}{lcccccc}
\hline & & \multicolumn{5}{c}{ Correlation } \\
N=340 Variable & Reliability. & $\boldsymbol{M}$. & SD. & $\mathbf{1}$ & $\mathbf{2}$ & $\mathbf{3}$ \\
\hline FPAVE & .815 & 4.1895 & .60573 & 1 & & \\
ANCAVE & .825 & 4.3012 & .54193 & $.408^{* *}$ & 1 & \\
INDAVE & .893 & 4.0433 & .67791 & $.323^{* *}$ & $.336^{* *}$ & 1 \\
\hline
\end{tabular}

** Correlation is significant at the 0.01 level (2- tailed).

\section{Hypothesis testing}

The regression tests for the control variables and the independent variables (direct effect) were done. The hypotheses tested the effect of Anchoring Heuristic on financial performance of Small and Medium Enterprises in Nairobi County, Kenya. The results in Table 2 showed that the predictors explained $51.7 \%$ of the variations on financial performance, $\mathrm{R}$-squared $=0.517$, Adjusted R-squared $=$ .508. The results also showed the coefficient of determination as significant as shown by $F=103.79, p$ 
$<0.001$. From the control variables, firm age was not significant but, in the industry, $(\beta=0.591, p<0.05)$ the results showed that it significantly influences the firm performance.

$\mathrm{H}_{\mathbf{0 1}}$ of this study states that Anchoring heuristic has no significant influence on the financial performance of SMEs in the County of Nairobi, Kenya. From the outcomes in the table below, anchoring heuristic has a positively significant effect on financial performance $\beta=0.129, p<0.005$. The $p$-value associated with the $t$ ratio was low consequently, the null hypothesis was rejected. This indicates that for every decision made using anchoring heuristic, there is a general increase of $12.9 \%$ in financial performance.

Table 2. Coefficients of estimates

\begin{tabular}{|c|c|c|c|c|c|c|c|}
\hline & \multicolumn{2}{|c|}{$\begin{array}{c}\text { Unstandardized } \\
\text { Coefficients }\end{array}$} & \multirow{2}{*}{$\begin{array}{l}\text { Standardized } \\
\text { Coefficients } \\
\text { Beta } \\
\end{array}$} & \multicolumn{4}{|c|}{ Collinearity Statistics } \\
\hline & $\beta$ & S. Error & & $\mathrm{T}$ & Sig. & Tolerance & $\begin{array}{l}\mathrm{VI} \\
\mathrm{F} \\
\end{array}$ \\
\hline (Constant) & 2.368 & .136 & & 17.454 & .000 & & \\
\hline Operational years & .060 & .032 & .084 & 1.897 & .059 & .934 & $\begin{array}{c}1.07 \\
0\end{array}$ \\
\hline Industry & .400 & .030 & .591 & $\begin{array}{r}13.32 \\
1\end{array}$ & .000 & .934 & $\begin{array}{c}1.07 \\
0\end{array}$ \\
\hline $\begin{array}{l}\text { ANCAVE } \\
\text { Summary statistics }\end{array}$ & .144 & .052 & .129 & 2.797 & .005 & .683 & 1.463 \\
\hline $\mathrm{R}$ & .719 & & & & & & \\
\hline R Square & .517 & & & & & & \\
\hline Adjusted R Square & .508 & & & & & & \\
\hline Std. Error of the Estimate & .424 & & & & & & \\
\hline Durbin- Watson & 1.996 & & & & & & \\
\hline ANOVA (F stat) & 103.79 & & & & & & \\
\hline Sig & .000 & & & & & & \\
\hline
\end{tabular}

Dependent Variable: Financial Performance

\section{Mediational testing}

In Hypothesis 1 testing, the study predicted that Investment Decision would mediate the connection between anchoring Heuristic with Financial performance of the SMEs. The study used Hayes 4 model to achieve the mediating effect and performed regression analysis on anchoring variable using PROCESS macro version 3.2 Model 4 (Hayes, 2018). The descriptive statistics for the variables were done, then correlation analysis to establish the relations among the variables. Furthermore, to determine the mediation effect, the MacKinnon (2012) four-step procedure was adopted. To attain robust standard errors for the parameter estimate, a bootstrapping technique was used by the researcher to test for the significance of the variables according to Hayes, (2018). The Bootstrapping produced $95 \%$ unbiased confidence interval of the effect using 5000 data re-samples. Hayes (2018), says that confidence intervals that don't have a zero in between, indicates effect that is positively significant at $\alpha=.05$, therefore, indicating partial mediation.

The results in Table 3 indicated that anchoring heuristic is significantly related to Investment decisions, coeff. $=.406, \mathrm{p}<.001$ (Table 3 of Model 1 ) with the model interpreting $12.8 \%$ of the variance, $\left(\mathrm{R}^{2}=.128\right)$ the covariate (Firm age) significantly associated with Investment decisions coeff $=-.086$, 
$\mathrm{p}<.05$ and one control variable being insignificant, which is presented as the first step. In step two, Investment decision was found to be positive and significantly related with financial performance with, coeff. $=.162, \mathrm{p}<0.001$ (Model 2 ). The industry type covariate was established to be positively significant with coefficient $=.346, \mathrm{p}<.001$. This model explained $48.0 \%$ of the variance, $\left(\mathrm{R}^{2}=.480\right)$. To establish the results in step three while we control for investment decisions, the Model 2 was used. The results show that anchoring heuristic was significantly linked to financial performance with, coefficient $=.239, \mathrm{p}<.001$. Lastly, results from the bias-correct percentile bootstrap technique showed that the indirect effect of anchoring heuristic on financial performance via investment decision was significant, $a_{i} \times b_{i}$ coeff. $=.066,95 \% C I=[.029, .112]$. The results point out a partial mediation. Additionally, Table 3 on Model 4 , gives the total effect $C^{\prime}+(a \times b)$ of the study results with anchoring heuristic having a coefficient $=.305, p<0.001$. The results of the control variables show the type of industry of SMEs has a positively significant effect on the financial performance of the SMEs.

Table 3: Mediating Effect of Investment Decision on the relationship between Anchoring heuristic and Financial Performance of SMEs in Nairobi County.

\begin{tabular}{|c|c|c|c|c|c|c|c|c|}
\hline Predictors & $\begin{array}{c}\text { Model } 1 \\
\text { (INDAVE } \\
\text { ) }\end{array}$ & & $\begin{array}{l}\text { Model } 2 \\
\text { (FP) }\end{array}$ & & $\begin{array}{c}\text { Model } 3 \\
\text { a1×b1 }\end{array}$ & & $\begin{array}{c}\text { Model } \\
4\end{array}$ & \\
\hline & $\beta$ & PV & $\beta$ & PV & & & $\beta$ & $\mathbf{P v}$ \\
\hline Constant & 2.250 & $(.000)$ & 0.895 & $(.000)$ & & & 1.261 & $(.000)$ \\
\hline Firm age & -.086 & $(.042)$ & 0.064 & $(.028)$ & & & .051 & $(.091)$ \\
\hline Industry & .071 & $(.085)$ & .346 & $(.000)$ & & & .358 & $(.000)$ \\
\hline ANCAVE & .406 & (.000) & .239 & $(.000)$ & $.406 \times .162$ & $=.066$ & .305 & (.000) \\
\hline INDAVE & - & - & .162 & $(.000)$ & & & - & - \\
\hline $\mathrm{R}$ & .357 & & .693 & & & & .672 & \\
\hline R2 & .128 & & .480 & & $\mathrm{CI}=.029$ & .112 & .451 & \\
\hline $\mathrm{F}$ & 16.395 & & 77.224 & & & & & \\
\hline Sig. & $(.000)$ & & $(.000)$ & & & & $(.000)$ & \\
\hline
\end{tabular}

Level of confidence for all confidence intervals in output: 95

Number of bootstrap samples for percentile bootstrap confidence intervals: 5000 .

\section{Discussion}

The outcomes from this study disclose that investment decision has a partial mediational effect on the link between anchoring heuristic and Financial performance of the Small and medium enterprises. This was brought about by the fact that the investors benchmark on the previous high rate of return achieved in the market to estimate the future return on investment which is the main motivating factor for investing in SME market. Furthermore, the investors respond quickly to change in investment decisions basing on the changes in investment pattern and also do research to know the trend of business before investing in a portfolio. Anchoring heuristic, results in significant increase in trading volumes Todd, et al. (2007), which in turn increases the liquidity of the firm. This came out of the observation that decision-makers tend to solve problems by forming a-priori estimates of what the answer might be. Shiller, (2000) results showed that investors tend to be optimistic in bull market and pessimistic in bear market. In the absence of solid information, investors set stock's price in relation to past price. These results agree to Shah and Oppenheimer (2008) who suggested that there is a relationship between anchoring heuristics and financial performance and that investors at times may apply simple rules that seem to work for them instead of applying 
complex models in decision making. The regression results, therefore, established that Anchoring heuristic has a positive and significant effect on financial performance.

\section{Conclusion}

This paper provides a research model of understanding the meditational role of investment decisions on the relationship between anchoring heuristic and Financial performance on SMEs. The study ratifies that anchoring heuristic association between investors and business opportunities can be used to shape and reinforce SME financial performance. These findings can help the investor fraternity to develop strategies that can outpace competitors in decision making, therefore, improving their financial performance of SME.

\section{Managerial and Theoretical implications.}

This paper confirmed what has already been established by other scholars that anchoring heuristic has a significant direct effect on Financial performance and Investment decisions of Small and Medium Enterprises. Moreover, the study brings in new knowledge that the Investment Decisions can mediate the association between anchoring heuristics and Financial performance of the SMEs. Besides, the individual investors who may benefit directly from the findings of this study, the small and medium enterprises can use these findings as locus for analysis and prediction of the trends of the investment market. Our results have positive and significant practical implications for individual investors; securities organizations; and the study of behavioral finance. Specifically, these findings demonstrate that the anchoring heuristics intensely affect Investment decisions, hence affecting the financial performance. Decision-makers should be conscious of the heuristic behavioral biases. Investors can also use the study to understand the power of representativeness heuristics on personal investment decisions and also to come up with models that relate the critical factors of heuristics to have informed investment decisions. Besides, both local and international financial governing authorities; the government; and supervisory agencies are probable to have a better understanding of the SMEs by appreciating the behavioral nature and investment decision patterns of the investors in this sector. Lastly, this paper is unique in the emerging economies, examining the mediating mechanism of Investment decisions on the association between anchoring heuristic and financial performance using the greatly demanding method of PROCESS macro for analysis.

\section{Recommendations}

This study pulls an overall picture of the impact of anchoring Heuristic on the financial performance and the mediating effect of the investment decisions on the association between anchoring Heuristic and the financial performance within Nairobi County. The future researchers ought to focus on the challenges that the investors face in the process of making investment decisions. A study could also be done to assess the effect of other factors that could affect SME investment decisions apart from the heuristic factors reflected in this study.

\section{Acknowledgment}

The author is highly grateful to Moi University for her administrative and technical support in the process of this study. 


\section{References}

Shiller, R. J. (2008). Derivatives markets for home prices (No. w13962). National Bureau of Economic Research.

Mussweiler, T. (2002). The malleability of anchoring effects. Experimental psychology, 49(1), 67.

Ross, S. A., Westerfield, R., \& Jordan, B. D. (2008). Fundamentals of corporate finance. Tata McGraw-Hill Education.

Ibrahim, A. B., \& Goodwin, J. R. (1986). Perceived causes of success in small business. American journal of small business, 11(2), 41-50.

Kotey, B., \& Meredith, G. G. (1997). Relationships among owner/manager personal values, business strategies, and enterprise performance. Journal of small business management, 35, 37-64.

Lambert, Q. (2012). Business models for an aggregator: Is an aggregator economically sustainable on gotland.

Kourtidis, D., Šević, Ž., \& Chatzoglou, P. (2011). Investors' trading activity: A behavioural perspective and empirical results. The Journal of Socio-Economics, 40(5), 548-557.

Waweru, N. M., Munyoki, E., \& Uliana, E. (2008). The effects of behavioural factors in investment decision-making: a survey of institutional investors operating at the Nairobi Stock Exchange. International Journal of Business and Emerging Markets, 1(1), 24-41.

Tversky, A., \& Kahneman, D. (1974). Judgment under uncertainty: Heuristics and biases. science, 185(4157), 1124-1131.

Fum, D., Del Missier, F., \& Stocco, A. (2007). The cognitive modeling of human behavior: Why a model is (sometimes) better than 10,000 words. Cognitive Systems Research, 8(3), 135-142.

Kahneman, D., \& Riepe, M. W. (1998). Aspects of investor psychology. Journal of portfolio management, 24(4), 52.

Fabozzi, F. J., Gupta, F., \& Markowitz, H. M. (2002). The legacy of modern portfolio theory. The Journal of Investing, 11(3), 7-22.

Osanloo, A., \& Grant, C. (2016). Understanding, selecting, and integrating a theoretical framework in dissertation research: Creating the blueprint for your "house". Administrative issues journal: connecting education, practice, and research, 4(2), 7.

Gall, M. D., Gall, J. P., \& Borg, W. R. (2014). Applying educational research: How to read, do, and use research to solve problems of practice. Pearson Higher Ed.

Garner, M., Wagner, C., \& Kawulich, B. (2016). Quantitative or qualitative: Ontological and epistemological choices in research methods curricula. In Teaching research methods in the social sciences (pp. 81-90). Routledge.

Jayawardhana, A. (2016). Financial Performance Analysis of Adidas AG. European Journal of Business and Management, 8(11), 74-82.

Al-Matari, E. M., Al-Swidi, A. K., \& Fadzil, F. H. B. (2014). The measurements of firm performance's dimensions. Asian Journal of Finance \& Accounting, 6(1), 24.

Babajide, A. A., \& Adetiloye, K. A. (2012). Investors' behavioural biases and the security market: An empirical study of the Nigerian security market. Accounting and Finance Research, 1(1), 219-229. 
Pachur, T., Bröder, A., \& Marewski, J. N. (2008). The recognition heuristic in memory-based inference: Is recognition a non-compensatory cue? Journal of Behavioral Decision Making, 21(2), 183-210.

Scott, S. G., \& Bruce, R. A. (1995). Decision-making style: The development and assessment of a new measure. Educational and psychological measurement, 55(5), 818-831.

Kumar, S., \& Rao, P. (2015). A conceptual framework for identifying financing preferences of SMEs. Small Enterprise Research, 22(1), 99-112.

Akben-Selcuk, E. (2016). Does Firm Age Affect Profitability? Evidence from turkey. International Journal of Economic Sciences, 5(3), 1-9.

Schuckert, M., Kim, T. T., Paek, S., \& Lee, G. (2018). Motivate to innovate. International Journal of Contemporary Hospitality Management.

Hayes, A. F. (2018). Partial, conditional, and moderated mediation: Quantification, inference, and interpretation. Communication Monographs, 85(1), 4-40.

MacKinnon, D. P., Coxe, S., \& Baraldi, A. N. (2012). Guidelines for the investigation of mediating variables in business research. Journal of Business and Psychology, 27(1), 1-14.

Todd, P. M., \& Gigerenzer, G. (2000). Précis of simple heuristics that make us smart. Behavioral and brain sciences, 23(5), 727-741.

Shiller, R. J. (2000). Measuring bubble expectations and investor confidence. The Journal of Psychology and Financial Markets, 1(1), 49-60.

Shah, A. K., \& Oppenheimer, D. M. (2008). Heuristics made easy: An effort-reduction framework. Psychological bulletin, 134(2), 207. 